\title{
Práticas educativas da capoeira no século XX: reflexões a partir de aspectos biográficos de mestres da arte
}

\begin{abstract}
Resumo: A capoeira, como possibilidade de manifestação recreativa, ginástica, esportiva, artística e(ou) sistema de defesa pessoal, possui uma potencialidade educativa que se evidencia pela característica de perpetuação e resistência cultural ao longo dos séculos. A fim de solucionar questionamentos relacionados à gênese dos métodos de ensino dessa prática, torna-se relevante uma análise de natureza qualitativa sobre aspectos da biografia de alguns expoentes da capoeira brasileira do século XX. Para tanto, foram adotados procedimentos técnicos de pesquisa em História, cujo objetivo centrou-se em refletir sobre práticas educativas da capoeira. Priorizou-se a seleção de fontes biográficas primárias que narrassem as histórias de vida de Bimba, Canjiquinha, Cobrinha Verde, Noronha, Pastinha e Waldemar, alguns dos inúmeros capoeiristas baianos que vivenciaram o início do processo de valorização social e de institucionalização da capoeira no século passado. A reflexão foi estimulada através do levantamento de informações sobre o início do aprendizado, concepção de capoeira, narrativas do ensino propriamente dito e possíveis correlações com aspectos de economia e de gênero. De acordo com essas categorias de análise, promoveu-se um direcionamento à compreensão do contexto histórico educacional que envolveu o processo de afirmação social dessa prática.
\end{abstract}

Palavras-chave: Ensino da Capoeira. História da Capoeira. Educação Básica.

\section{Introdução}

Devido ao potencial educativo da capoeira, consideramos relevante uma reflexão sobre o modo de ensino de antigos capoeiristas que são reconhecidos como mestres da cultura popular perante a sociedade brasileira. Essa reflexão faz-se necessária para que haja um maior entendimento da gênese do pensamento educacional e dos métodos de ensino dessa prática. Portanto, interpomos as seguintes questões norteadoras: "Que elementos histórico-educacionais estão presentes na oralidade dos mestres que vivenciaram o início da inserção social da capoeira? "; "Que métodos de ensino eram utilizados?".

A fim de solucionar essas questões, realizamos uma análise de natureza qualitativa sobre aspectos da biografia de alguns expoentes da capoeira brasileira do século XX. Para tanto, adotamos procedimentos técnicos de pesquisa em História. Conforme Polak, Santana e Araújo (2011), o olhar do historiador consiste numa problematização formulada no tempo presente que só poderá ser
Sammia Castro Silva Instituto Federal de Educação, Ciência e Tecnologia (IFCE)Campus Canindé (CE) sammiacastroef@gmail.com José Gerardo Vasconcelos Programa de Pós-Graduação em Educação da Universidade Federal do Ceara (PPGE - UFC)

gerardovasconcelos1964@gmail. com 
solucionada recorrendo-se aos acontecimentos passados. Não há interdependência com a formulação de uma cronologia rigidamente periodizada, mas há a necessidade de um recorte temporal. Nessa modalidade de pesquisa, há a liberdade de reformulação e criação de conceitos, mas as escolhas não são aleatórias nem arbitrárias, visto que devem ser resultantes de uma articulação entre as evidências teórico-metodológicas e a busca incessante por respostas ao objeto e problema formulados.

A pesquisa em História tem uma íntima relação com documentos primários e quaisquer outras fontes que possibilitem a compreensão global dos acontecimentos e do que é relevante para o conhecimento do objeto de estudo. Diante desses pressupostos metodológicos, priorizamos a seleção de fontes biográficas primárias que pudessem representar os inúmeros capoeiristas baianos que vivenciaram o ensino da capoeira ainda sob o escopo da marginalização e informalidade. Recorremos às obras dos seguintes autores: Abreu (2003), Almeida (1994), Canjiquinha (1989), Coutinho (1993), Pastinha (1960) e Santos (1991), as quais nos mostram concepções filosóficas e metodológicas de ensino que pretendem promover a compreensão da contextualidade histórica em que viveram esses sujeitos e nos inserir nos mecanismos de ensino-aprendizagem da capoeira.

Em Santos (1991), encontramos relatos biográficos coletados por Marcelino dos Santos, discípulo do mestre Cobrinha Verde. Observamos nessa obra o aspecto lendário da oralidade desse mestre, que narra os ensinos da capoeira num contexto de transição da marginalidade para a descriminalização da prática através da própria história de vida.

Em seguida, a obra de Canjiquinha (1989) nos insere nos manuscritos autobiográficos desse mestre, conectando-nos com a metodologia de ensino da capoeira a partir da década de 1935, quando era praticada informalmente em frente a bares e em feiras populares dominicais.

Prosseguindo com a pesquisa, abordamos o estudo biográfico de mestre Bimba e as manifestações ritualísticas implementadas por esse capoeirista. Optamos por utilizar Almeida (1994), um dos mais exímios alunos desse mestre, conhecido nas rodas de capoeira como mestre Itapuã.

A seleção de obras historiográficas de mestres da capoeira do século XX progride com Pastinha (1960), relíquia histórica que é 
composta por desenhos e manuscritos autobiográficos deste. Mestre Pastinha também é visto como uma das personalidades históricas propulsoras da elevação do status da capoeira na sociedade, devido à sua postura ética e compreensão filosófica da prática. Observamos que a trajetória e os manuscritos desses mestres se coadunam, demonstrando uma versatilidade de concepções que transitam entre os princípios da contextualidade da popularização do ensino da Educação Física naquele século, seja ela permeada por valores ginásticos ou esportivos, e os princípios da relevância das manifestações artísticas populares brasileiras na sociedade.

Dessa forma, pudemos selecionar a obra de Coutinho (1993), que desvela enredos dos aspectos ginásticos e esportivos da capoeira em formato de manuscritos autobiográficos do lendário e popular mestre Noronha. Observamos o contexto histórico em que as vivências de ensino-aprendizagem desse mestre são enunciadas.

Por fim e para ratificar as inter-relações existentes entre arte, luta e jogo na capoeira, atemo-nos à obra de Abreu (2003) e à relevância sócio-histórica das narrativas biográficas do mestre Waldemar Rodrigues da Paixão.

A análise de dados desta pesquisa em história educacional foi inteligibilizada a partir do levantamento de informações sobre o início do aprendizado, concepção de capoeira, narrativas do ensino propriamente dito e possíveis correlações com aspectos econômicos, religiosos e de gênero. Concluímos este artigo sintetizando as reflexões e encaminhando direcionamentos para a compreensão mais detalhada da prática da capoeira no século XX.

\section{Revisão de literatura}

O ato de ensinar a capoeira, como elemento da cultura popular brasileira, esteve numa perspectiva oposta à proposta inicial de formulação do sistema educacional brasileiro. O modelo tradicional de ensino e a ilegalidade da capoeira, com a proibição estipulada pelo Código Criminal do Império e com o Código Penal da República do Brasil de 1890, validaram tal informação. Contudo, na contextualidade da busca pela autenticidade racial e cultural brasileira da Era Vargas, a capoeira iniciou um processo de aproximação com o sistema formal de ensino no século XX.

Atualmente a capoeira tem recebido recorrentes manifestações de valorização, constatadas por um número considerável de 
produções acadêmicas e por políticas públicas culturais. Além do aspecto lúdico, frequentemente associado ao ensino da capoeiragem no decorrer dos diferentes períodos históricos, também há o movimento ginástico-militarista e esportivista. Nesse sentido, destacamos a perspectiva ideológica de intelectuais e militares para a implementação da capoeira como a autêntica ginástica brasileira.

Constituem exemplos de manuais de ginástica envolvendo técnicas de capoeira, consoante Capoeira (1998), o Guia da capoeira ou Ginástica brasileira, do Quartel Mata-Porcos, em 1907, exercitado por oficiais e praças, e um manual de capoeira para uso exclusivo dos militares, elaborado pelo capitão Ataliba Nogueira e assessorado pelos tenentes Lapa e Leite. Posteriormente, em 1920, Mário Aleixo publicou seu manual no periódico Eu sei tudo, incorporando golpes de jiu-jítsu, boxe e jogo do pau português. Em 1928, Annibal Burlamaqui publicou Ginástica nacional: capoeiragem metodizada e regrada, incorporando também novos elementos à prática da capoeira.

O movimento ginástico europeu, também conhecido por higienismo, abordava a atividade física como meio de regeneração da raça e subsídio para melhorias da saúde. Estando a serviço de um mecanismo político, sistematizou uma rede de saberes que visavam obter também a ordem e o disciplinamento nas instituições que exerceriam profundo controle da sociedade, ou seja, no exército e na educação. Conforme Darido (2005), esse modelo de Educação Física foi introduzido no currículo escolar brasileiro por ocasião da Reforma Couto Ferraz, em 1851. Entretanto, foi implementada de fato somente a partir de 1882 nas escolas normais e militares, sob o viés da ciência ginástica, que pretendia instigar a força e a coragem do povo para a defesa da pátria.

Consoante Silva (2013), o intercâmbio ideológico entre militares, capoeiras e intelectuais existiu desde o período imperial e explica-se pelos interesses que ora convergiam, ora divergiam nos diferentes setores da sociedade. O fato é que, com a Proclamação da República, em 1889, os capoeiristas foram extintos das ruas do Rio de Janeiro pela atuação de Sampaio Ferraz, lendário chefe de polícia, e pela publicação do Código Penal da República, que tornou a capoeira crime no artigo 402. Conforme Dias (2001), nos primeiros 40dias de República, foram deportados 1 mil e 300 capoeiras para a ilha de Fernando de Noronha. Apesar da repressão aos capoeiristas, 
intelectuais continuaram a exaltar o potencial educativo da capoeira e os militares a utilizá-la, explorando o aspecto ginástico e esportivo.

De acordo com Brasil (2007), a vertente nacionalista da Belle Époque, ${ }^{1}$ tendo Coelho Neto como um de seus representantes, por volta de 1910, defendia a capoeira como a autêntica ginástica brasileira e verdadeira Educação Física do Brasil, devendo ser ensinada nas escolas e quartéis ou em qualquer outro lugar onde a instrução fosse importante. Apesar de intelectuais do círculo de amizades de Coelho Neto ridicularizarem essa ideia, o movimento modernista, iniciado em 1922 na Semana de Arte Moderna em São Paulo, valorizou elementos culturais do cotidiano da realidade brasileira e adquiriu notório destaque, promovendo a ascensão desse novo momento cultural.

Ainda na década de 1920, Mello Moraes Filho, autor do texto "Tipos da rua: capoeiragem e capoeiras célebres", corroborou publicamente a ideia de que a capoeira era a luta própria do Brasil, e mestre Sinhozinho, eliminando canto e instrumentos musicais, manteve uma academia em Ipanema de 1920 à década de 1960. Diante dessa contextualidade, é interessante ressaltar que, nesse mesmo período, o ensino e a prática da capoeira já estavam consolidados de diferentes maneiras e concepções na Bahia. Poderemos perceber o modo como ocorriam tais práticas educativas a partir da análise das obras selecionadas.

\section{Análise de dados}

\subsection{Cobrinha Verde}

Em Santos (1991), encontramos que Rafael Alves França, mestre Cobrinha Verde, nasceu no primeiro decênio do século XX na Bahia, numa localidade chamada Santo Amaro da Purificação. Iniciou o aprendizado na capoeira aos 4 anos de idade com o lendário Besouro Mangangá, primo carnal e irmão de criação. Afirmavase que Besouro dava aula escondido da polícia e que, quando os agentes da lei chegavam, os alunos costumavam fugir, havendo inclusive ocasiões em que Besouro precisava enfrentá-los sozinho.

Aos 17 anos de idade, teve uma briga com o delegado de polícia. Após esse episódio, fugiu de Santo Amaro e se incorporou ao bando de Horácio de Matos, vivenciando as histórias que permeiam o fenômeno do cangaço e da Revolução de $1930^{2}$, como a
(1) Movimento literário, político e cultural brasileiro influenciado pelo movimento histórico francês de paz, de avanços tecnológicos e de valorização artística que se estendeu de 1880 ao início da Primeira Guerra Mundial. No Brasil, a Belle Époque se instaurou e influenciou a cultura nacional a partir do início da República Velha, perdurando, em meio às composições literárias oficiais e pré-modernistas, até ser iniciado o Movimento Modernista em São Paulo. A literatura oficial estabeleceu uma estreita relação com grupos políticos e instituições públicas, a exemplo da Academia Brasileira de Letras, à qual eram comumente destinadas críticas devido ao caráter servil das obras, que tinham a clara finalidade de adquirir ascensão social, respeitabilidade pública e incorporação aos centros de poder da época. Paralelamente à literatura oficial, havia no período da Belle Époque uma vertente pré-modernista que, segundo Silva (1996), optava pelo afrontamento ou simples distanciamento das instituições acadêmicas, preferindo os assentos menos formais das confeitarias e cafés para discussão de diversos temas, entre eles a problematização do cotidiano da realidade nacional

(2) Golpe de estado relacionado ao movimento tenentista que impediu a posse de Júlio Prestes, presidente eleito com apoio das oligarquias paulistanas. No dia 3 de novembro de 1930, Getúlio Vargas assumiu a chefia do Governo Provisório da República, pondo fim ao período da República Velha e nomeando os principais líderes tenentistas como interventores nos estados do Nordeste, por exemplo: Juarez Távora no Ceará e Juracy Magalhães na Bahia. 
Guerra de São Paulo de 1932. A participação nas tropas aliadas ao governo de Getúlio Vargas lhe rendeu o posto de terceiro sargento e a responsabilidade de cuidar da cocheira de animais e cavalos do quartel de Campo Grande, em Salvador. Posteriormente um conflito com um tenente do exército the fez abandonar o posto e voltar a exercer sua antiga profissão de pedreiro. (SANTOS, 1991)

Para o mestre Cobrinha Verde, a capoeira nasceu na região do Recôncavo Baiano, precisamente em Santo Amaro e Cachoeira, criada pelos africanos escravizados. Advinda da dança do batuque, a capoeira teve seus primeiros golpes similares aos seguintes passos: balão de linha de calça, banda de lado, banda traçada e rasteira. Com o passar do tempo, os africanos foram estudando, treinando e adaptando novos golpes. Na compreensão desse mestre, a capoeira não é esporte, mas sim uma luta e uma defesa pessoal, com muitas artimanhas secretas que não oferecem chance de o outro se defender. Um aspecto curioso mencionado por ele foi que Besouro, antes de morrer, teria chamado vários discípulos e pedido para que Cobrinha Verde o fizesse feliz eternamente ao ensinar capoeira de graça. Por amor a Besouro, assim fez por toda a vida. (SANTOS, 1991)

Para Cobrinha Verde, o mestre mais famoso de Santo Amaro foi tio Alípio, escravo no Engenho de Pantaleão e mestre do famigerado Besouro Mangangá. Os treinamentos dos antigos capoeiras envolviam o enfrentamento de uma situação real de perigo. Havia uma prática educativa que Besouro costumava fazer com os alunos avançados que foi descrita da seguinte forma: "...] se fechava numa sala com o discípulo, metia a mão num punhal e dava outro ao discípulo e dizia: 'Vamos trocar facas com uma toalha amarrada na cintura dos dois, pra [sic] um não fugir do outro". (SANTOS, 1991, p. 15) A união entre magia e religiosidade relacionada à prática capoeirística, através do aprendizado de breves orações e patuás, fazia-se necessária para defender-se das balas e de outros possíveis perigos. (SANTOS, 1991)

Na época da entrevista, mestre Cobrinha Verde estava aposentado e com a preocupação de não passar dificuldade financeira como haviam passado os mestres Pastinha e Bimba. Ele lembrava que naquela época já se podia achar capoeira na liberdade, pois ela já não era mais cativa como os negros eram quando vieram da Costa da África. Contudo, a vivência nos movimentos armados do sertão e os relatos de perseguição policial enfrentados por ele e 
seu mestre Besouro o aproximaram das memórias sobre a condição marginalizada da capoeira. Por isso, Santos (1991) costumava dizer que Cobrinha Verde queria ser igual a Besouro e a Lampião, sendo o primeiro rei da capoeira e o segundo rei do cangaço. Ancestralidade, memória, oralidade e conhecimento histórico, político e cultural da sociedade brasileira do século XX são marcas presentes na obra analisada, entre outros elementos.

\subsection{Canjiquinha}

Canjiquinha, alegria da capoeira: eu sou a alegria da capoeira, na capoeira eu sou a alegria é uma publicação da editora A rasteira. Trata-se das concepções escritas do mestre Canjiquinha, cujo nome é Washington Bruno da Silva, nascido em 1925 nas imediações do Pelourinho. Mestre Canjiquinha encontrou a capoeira num domingo do ano de 1935 em frente ao banheiro do bar de Otaviano, numa localidade chamada Baixa do Tubo de Matatu Pequeno, em Brotas. Os capoeiristas que costumavam se exercitar nessa localidade eram conhecidos por Silva Boi, Zé de Brotas, Onça Preta, Rosendo, Chico Três Pedaços, Dudu, Maré e Aberrê. Após oito anos consecutivos de aprendizado com Aberrê, Canjiquinha foi instruído a procurar outras fontes de aprendizado, tornando-se, depois de 16 anos de treinamento, contramestre de Pastinha e do próprio mestre Aberrê.

Para mestre Canjiquinha, a compreensão da capoeira assumia um caráter múltiplo e abrangente dentro do universo educativo. Primeiramente ele mencionava o entendimento de que a capoeira era uma luta criada pelo povo negro para se livrar com arte da escravidão, podendo se utilizar de pau, navalha, faca ou facão. Em seguida, ressaltava que ela era uma brincadeira que se tornava melhor ao ser prestigiada por um público. Posteriormente afirmava que o único esporte brasileiro era a capoeira, asseverando também que ela era uma dança, uma Educação Física, a qual se tornava folclore se tivesse berimbau e pandeiro. Segundo ele: "A capoeira é alegria, é prazer [...] é aquilo que você faz por espontaneidade, vontade e alegria [...]. A capoeira é alegria, encanto e segredo. É esporte, lazer, uma luta quando não tem berimbau". (CANJIQUINHA, 1989, p. 78-82)

Mestre Canjiquinha se autointitulava como "A alegria da capoeira", ressaltando a importância do riso no aprendizado e dizendo que havia aprendido dando risada e que também ensinava dessa forma. O ensinamento desse mestre ocorria inicialmente com o 
conhecimento sobre a base da capoeira, que significava "começar de baixo" e ensinar primeiros golpes e defesas. Canjiquinha ressaltava que a capoeira deveria ocorrer de acordo com o toque do berimbau, devendo-se ter bastante atenção no momento do jogo, ou seja, dever-se-ia jogar estudando o jeito do oponente, de preferência a um metro de distância, essencial para que cada um adquira a habilidade de se defender. (CANJIQUINHA, 1989)

No universo da prática educativa desse mestre, também havia um sistema de enfrentamento a uma situação real de perigo conhecida por "Quebrar no Beco". Tal prática consistia em mandar outros alunos pegá-los na rua, essencialmente onde houvesse becos de acesso, para fazer um teste. Por isso, seus alunos não passavam encostados em becos; eles afastavam-se pelo menos uns dois metros. Esse mestre ressaltava os efeitos psicológicos benéficos da prática da capoeira, dizendo ser boa para evitar tédio, estresse, irritação, limpar a memória e conviver entre amigos. Canjiquinha (1989) afirmava ter tido muitas alunas, entre elas uma professora de ginástica conhecida por Fátima; além dela, citou o nome de célebres capoeiristas, como: Maria 12 homens, que havia brigado com 12 policiais na Baixa dos Sapateiros; Maria Avestruz, que morava na Boca do Rio; Palmeirão, que havia matado Pedro Porreta e morava na rua 28 de setembro. (CANJIQUINHA, 1989)

Ainda sobre o aspecto profissional, esse mestre realizou a seguinte profecia:

Capoeira tem começo, mas não tem fim. Daqui a 30 anos, ela vai ter princípio e fim, depois que regularizar tudo não vai exceder do espaço traçado. Mas como ela está como folclore e esporte, você sabe como começa, mas não sabe como termina. (CANJIQUINHA, 1989, p. 78)

Canjiquinha (1989) ressaltou que seu sustento financeiro não era proveniente da capoeira, haja vista que o ato de ensinar a capoeira não rendia riquezas financeiras:

Bimba era marceneiro, Valdemar trapicheiro, Caiçara funcionário. Como foi que Pastinha morreu? À míngua. Como foi que Bimba morreu? À míngua. Cobrinha Verde? À míngua. Valdemar está em dificuldades. Se não trabalhar, morre de fome. (CANJIQUINHA, 1989, p. 78) 
Canjiquinha dizia que ele foi quem primeiro havia colocado o samba de roda e a puxada de rede na capoeira, posteriormente teria posto o samba de caboclo e o maculelê. Esse mestre criou o grupo folclórico Aberrê Bahia, que era repleto de demonstrações da cultura afrodescendente. Ele dizia ter aprendido toda essa cultura com a mãe, a irmã e a tia, que eram candomblecistas. Já a puxada de rede havia aprendido numa localidade nomeada Jardim de Alá, chamada antigamente de Chega Nego, onde qualquer pessoa podia entrar e ajudar a puxar a rede do pescado. Esse mestre criou o Muzenza e o Samango, dois tipos diferenciados de toque e jogo de capoeira, cuja inspiração também veio do candomblé. (CANJIQUINHA, 1989) Esse mestre demonstra a diversidade das práticas corporais afro-brasileiras que constituem o fenômeno da capoeira, além do binômio ginástica-luta, e a presença da capoeira nos grupos folclóricos da Bahia no século XX.

\subsection{Mestre Bimba}

Conforme Almeida (1994), em 23 de novembro de 1900, no bairro Engenho Velho, nasceu Manoel dos Reis Machado, mestre Bimba, filho de Luiz Cândido Machado, exímio dançador de batuque, e Maria Martinha do Bonfim. Aos 12 anos de idade, iniciou-se na capoeira com o africano Bentinho, capitão da Companhia de Navegação Baiana. Bimba começou a trabalhar como estivador aos 13 anos de idade e assim permaneceu pelos próximos 14 anos. O início do ensino dessa prática ocorreu em 1918, no Engenho Velho de Brotas, a 30 homens que o acompanhavam e que juntos formavam o Clube da União em Apuros. Criou a capoeira regional da união entre o batuque e a capoeira Angola.

A partir de 1934, foram inúmeras as matérias em jornais que se referiam aos desafios e vitórias de mestre Bimba no ringue; numa reportagem do Diário da Bahia veiculada em 13 de março de 1936, ele afirmou ter conhecimento do Manual de Capoeiragem de AnnibalBurlamaqui, ou Zuma, editado em 1928 nos quartéis militares do Rio de Janeiro. Através do seu aluno Sisnando, cearense, teve contatos influentes que lhe possibilitaram registrar sua academia na Secretaria da Educação, Saúde e Assistência Pública da Bahia em 1937. (ALMEIDA, 1994)

No jornal A Tarde da cidade de Salvador, em 7 de fevereiro de 1946, afirmou que a capoeira não tinha a essência de uma luta de ringue, pois servia para atuações decisivas. Mencionou nessa 
reportagem alguns aspectos técnicos da prática, como o domínio do corpo através do controle dos golpes, a ginga e as artimanhas da capoeira antiga. A eficácia do método criado por Bimba foi comprovada em diferentes momentos, especialmente em 1949, quando muitas notícias de jornais descreveram as vitórias dos combates entre capoeiristas e lutadores de outras modalidades esportivas, entre elas o jiu-jítsu. Demonstrações da capoeira por todo o país, inclusive para inúmeras autoridades, eram frequentes na década de 1950, conferindo uma aproximação da capoeira regional com o universo das apresentações folclóricas. (ALMEIDA, 1994)

Aspectos filosóficos do ensino de Bimba são enfatizados por antigos alunos, tais como Almeida (1994, p. 58), mestre Itapoã: "[...] o brilho, o carisma, a força interior, a capacidade de transformar simples adolescentes em homens de verdade, a paciência em transformar dificuldades em filosofia de vida". Mestre Bimba demonstrou ser bom pesquisador, pois estudou a capoeira e criou um método com aspectos ritualísticos, valorizando também princípios éticos e morais. Para ser seu aluno, o sujeito deveria ser estudante ou trabalhador, além de ser aprovado também num exame por ele realizado. (ALMEIDA, 1994)

Os treinos de Bimba eram conduzidos com um berimbau e dois pandeiros, também chamados de bodes. Os atabaques, confeccionados para o candomblé da esposa, dona Alice, também eram utilizados para o samba de roda e os festejos do centro. O misticismo de Bimba também era expresso no escudo do seu Centro de Cultura Física Regional, inspirado no Signo de Salomão. (ALMEIDA, 1994)

A fatalidade que marca o aspecto profissional de mestre Bimba ocorreu quando promessas de melhorias o fizeram deixar todo o legado construído na Bahia para ir a Goiânia. Haviam-lhe prometido uma academia com vários alunos matriculados, casas mobiliadas, colégios bons para os filhos estudarem e um cargo de professor de Educação Física na Universidade de Goiás. Todavia, o que aconteceu na verdade foi que mestre Bimba foi enganado por essas falsas promessas e não pôde voltar para a Bahia posteriormente, porque já havia se desfeito de todos os bens que ali possuía.

Fala-se que o mestre morreu de tristeza, popularmente chamado banzo, mas o fato é que se precisou de um balão de oxigênio enquanto esteve internado, e a família não teve condições financeiras de pagar por esse artefato médico. Contudo, mestre Bimba fez cumprir sua palavra quando saiu da Bahia, ao dizer que não 
voltaria mais devido ao fato de nunca ter sido lembrado pelos poderes públicos; segundo ele, se em Goiás não gozasse de nada, iria gozar do cemitério. (ALMEIDA, 1994)

\subsection{Mestre Pastinha}

Os ensinamentos desse mestre eram repassados pela musicalidade, pela oralidade dos alunos que ajudou a formar bem comopelos manuscritos e desenhos. (PASTINHA, 1960) Questões éticas faziam parte dos ensinamentos desse mestre, que costumava dar visibilidade e valorizar um estilo mais tradicional de jogar capoeira, ao passo que também contribuía para uma nova tradição que emergia. Dentro do aspecto prático de seu método de ensino, o elemento ritualístico e lúdico da roda de capoeira assumia uma grande importância, em que o conjunto musical se apresentava composto por berimbau, pandeiro, reco-reco, agogô, atabaque, chocalho. Muitos cantos que antecedem o jogo da capoeira, as ladainhas, foram criados por mestre Pastinha e possuem caráter de ancestralidade, louvando a Deus e os mestres antigos.

Conforme Pires (2002), esse mestre nasceu no dia 5 de abril de 1889 e começou a treinar capoeira aos 10 anos de idade com um angolano nomeado Benedito. Era filho de um espanhol nomeado Pastinhã, que exercia o ofício de mascate, e de uma negra natural da Bahia, Raimunda dos Santos. Pastinha vivenciou um contexto político em que a capoeira era perseguida pela força policial. Ele foi aluno da Escola de Aprendizes Marinheiros dos 12 aos 20 anos, onde afirmava ter ensinado capoeira aos colegas. Mestre Pastinha se considerava um artista, sendo pintor, engraxate, vendedor de gazeta, garimpeiro, trabalhador na construção do porto de Salvador e segurança de uma casa de jogo. Após um longo período sem visibilidade na capoeiragem baiana, 1920 a 1940, ${ }^{3}$ Pastinha ressurgiu como um grande líder e foi um dos fundadores do Centro Esportivo de Capoeira Angola.

Em 24 de março de 1944, mestre Pastinha fez nova tentativa de fazer prosperar um centro de Capoeira Angola, mas somente em 1949 obteve sucesso nesse empreendimento. (PASTINHA, 1960) Segundo Pires (2002), mestre Pastinha afirmava que a capoeira Angola era um esporte originado da dança primitiva dos caboclos, do batuque e do candomblé, assumindo também a contribuição de congoleses, moçambicanos e indígenas na formação de uma capoeira mais lúdica e defensiva. Em entrevista ao jornal Estado de
(3) A década de 1930, na Bahia, foi permeada por acontecimentos marcantes no cenário capoeirístico angoleiro. Exemplos disso foram a inauguração do Parque Odeon e o apoio dos intelectuais ligados à esquerda política da época, envoltos nos estudos sobre as relações raciais no Brasil, tais como Caribé, Jorge Amado e Edson Carneiro. Houve, em 1937, a participação do lendário Samuel Querido de Deus, entre outros angoleiros famosos, no $2^{\circ}$ Congresso Afro-Brasileiro, organizado por Edson Carneiro, momento em que este apresentou trabalho sobre a Capoeira Angola. 
São Paulo, teria dito que do índio a capoeira ganhou principalmente as defesas, como a negativa, a queda para trás e a defesa com as mãos. Outra influência indígena foi a adoção do berimbau nesse formato de arco que conhecemos, pois na África o berimbau teria o formato de um "S", com fio de fibra e sem caixa de ressonância feita de cabaça, artefato que teria sido encontrado apenas aqui no Brasil.

Os manuscritos de Pastinha datam da década de 1960 e são intitulados Quando as pernas fazem miserêr:metafísica e prática da capoeira. Pastinha dizia que havia presenciado a capoeira amofinar e perder o valor pela falta de princípios éticos no início do século XX. O Centro de Capoeira Angola pretendia desenvolver a capoeira pelo entendimento de ser a capoeira um esporte que tinha a nobre vantagem de ter sido legado pelos nossos antepassados para a defesa da própria integridade física.

O bom capoeirista nunca se exalta, procura sempre estar com calma para poder refletir com precisão e acerto, não discute com seus camaradas ou alunos, não toma jogo sem ser sua vez para não aborrecer, nem surgir rixa [...], a nossa causa é a causa da moralização e aperfeiçoamento desta luta, tão bela quanto útil, a nossa Educação Física [...]. A união faz a força, portanto só devemos ter em mente a prosperidade do nosso centro, e isso só podemos adquirir com perseverança, desprendimento e força de vontade para realizarmos nosso ideal de uma capoeira perfeita, de uma raça forte e sadia, que num futuro próximo daremos a nosso amado Brasil. (PASTINHA, 1960, p. 11-12)

Sobre a questão de gênero, Pastinha (1960, p. 10) ressaltou: "Todos nascem com a capoeira, não só os homens como as mulheres. Está gravada na história mulheres que jogavam a mandinga e batucavam, Maria Homem, Júlia, vulgo Fugareira[...]". O Centro Esportivo de Capoeira Angola foi oficializado em 1952 no livro Civil do Pessoal Judicial. O primeiro presidente foi Atalídio Caldeiras, intelectual baiano, sendo Paulo Santos Silva um dos principais idealizadores do estatuto, que tinha como base fundamental a boa conduta e a capoeira Angola como símbolo nacional. Pastinha também esteve em vários estados brasileiros para apresentações artísticas e no continente africano em 1962, na região de Dakar. Em 1967, ficou cego, e a academia entrou em decadência, assim como as próprias condições financeiras do mestre. No decorrer da velhice, viveu situações miseráveis, falecendo em 1981. Inúmeros capoeiristas fizeram apresentações para auxiliar o velho mestre 
enquanto vivo, como João Grande, João Pequeno e até mesmo mestre Bimba. (PASTINHA, 1960)

\subsection{Mestre Noronha}

Mestra Noronha, cujo nome de batismo é Daniel Coutinho, nasceu em 3 de agosto de 1909 numa localidade chamada Baixa dos Sapateiros, Bahia, e iniciou o aprendizado da capoeira aos 8 anos de idade com o mestre Cândido Pequeno. Como principal fonte de estudo que utilizamos a respeito desse mestre, recorremos aos próprios manuscritos deixados por ele e publicados em 1993. Mestre Noronhadiziaque a capoeira é um esporte popular do Brasil presente em todas as classes sociais, nos ginásios, colégios, universidades e estabelecimentos comerciais e industriais, uma espécie de Educação Física da polícia, exército e marinha, estando sempre em crescente popularidade em virtude da incomparável eficiência de ataque e defesa.

Devido ao fato de ter se iniciado na capoeira no início do século XX, empoderou-se das narrativas das vivências de transição entre a época em que a capoeira era odiada pelo governador e pela polícia e a época em que ela se inseriu em diferentes meios sociais e se expandiu pelo mundo inteiro. Para mestre Noronha, a capoeira foi trazida da África e educada na Bahia para a defesa pessoal, lugar onde nasceram os melhores mestres de Capoeira Angola do Brasil. Afirmava que os negros africanos brincavam na hora da folga para os senhores de engenho, atestando que a capoeira sempre foi receptiva a espectadores.

Seu mestre, Cândido Pequeno, era filho de um negro da Angola com uma africana da Bahia, o qual costumava usar uma argolinha de ouro como símbolo das inúmeras vitórias na capoeira. Esse mestre dizia que tinha capoeira em todo porto brasileiro e freguesia, cuja utilidade foi comprovada pela oralidade dos capoeiristas antigos. Reportou o momento em que os escravos mandingueiros haviam sido convocados para o Batalhão Quebra Pedras, com a finalidade de expulsar os portugueses do território. Muitos daqueles escravos não tinham armas de fogo, apenas a habilidade da capoeira, utilizando-se de pontapés, rasteiras, cabeçadas, rabos de arraia, pedradas e cacetes, sagrando-se vitoriosos sob o comando do general Labatu. Outro momento também rememorado por mestre Noronha foi a eficiência dos serviços prestados pelos capoeiristas ao Brasil durante a Guerra do Paraguai. 
Coutinho (1993) relatou uma série de festas tradicionais em que a capoeira se manifestava na Bahia, reconhecendo a importância da força policial no combate aos atos de violência dos desordeiros nessas festas populares, enfatizando os atos de violência da festa de Santa Luzia. A religiosidade desse mestre expressava-se pelas constantes afirmações de que tinha o corpo fechado e de que sempre estava com as obrigações em dia para o orixá de devoção. Utilizava como simbologia uma estrela de cinco pontas, com uma cruz na região superior e as iniciais JMJ, que significavam Jesus, Maria, José.

Mestre Noronha reconhecia a existência de sete toques de berimbau que manipulavam toda a movimentação dentro da roda, a saber: jogo de dentro: jogo de grande observação; São Bento Grande: para armar golpe; São Bento Pequeno: para desfazer golpe; apanha laranja no chão, tico-tico: um jogo baixo e alto; este negro é o cão: jogo violento; Samba de Angola; Quebra milho como gente, macaco.

Para ele, os segredos da Capoeira Angola representavam um privilégio dos velhos mestres, sendo o berimbau também uma arma para a defesa, em que a verga e a própria baqueta tinham sua utilidade no momento de precisão. Outros aspectos citados foram os conhecimentos a respeito do uso da navalha, arma curta e ligeira que não deve ser utilizada em exibição pública de capoeira, pois é um segredo. A referência ao cachecol de seda ao pescoço também foi mencionada como instrumento de defesa contra a navalha.

Conforme os próprios relatos, trabalhou de engraxate, trapicheiro, carregador, entre outros cargos, para poder se manter financeiramente; na época da elaboração de seus manuscritos, em 1970, estava aposentado dos serviços nas docas. Apesar dos 65 anos de idade, afirmava nunca ter desprezado sua vocação de mestre de capoeira nem o amor à pátria.

Naquela década, a concepção da capoeira como modalidade esportiva viveu seu tempo áureo, tanto que mestre Noronha exaltava o surgimento de uma "Federação Brasileira de Capoeira Angola", com vistas a congregar as academias da Bahia. Esse mestre mencionava alguns aspectos regulamentares dessa luta conforme o entendimento que tinha, fazendo também menção ao papel do juiz - termo utilizado também por mestre Pastinha - no jogo da capoeira Angola. Para mestre Noronha, o ringue teria $4 \mathrm{~m}^{2}$, sendo conferido dois pontos ao jogador que fosse superior em ataque e três àquele que derrubasse o adversário. 
O esporte, como um instrumento ideológico do estado, manifesta-se de forma intensiva no decorrer da década de 1970, período da ditadura militar. O fato é que muitos dos mestres antigos - que relataram o amor à pátria e defenderam a inserção da capoeira no contexto esportivo - não se deram conta do risco que haviam corrido quando aquele sistema político se apropriou dos ensinamentos da capoeira no sentido de tornar a importância dos ensinamentos dos antigos mestres secundária.

\subsection{Mestre Waldemar}

De acordo com Abreu (2003), Waldemar Rodrigues da Paixão nasceu em 1916 e viveu por 74 anos. Waldemar conheceu a capoeira em Periperi, subúrbio de Salvador, em 1936. Iniciou-se em aclamadas rodas dominicais e de um modo similar àquele que contou mestre Canjiquinha, rememorando que comprava duzentos réis de vinho tinto e o oferecia em troca de alguns ensinamentos. Havia grande expectativa entre os aspirantes a capoeiristas de se obter experiências práticas daquela arte, havendo sempre um momento em que algum exímio jogador pegava nas mãos de um aluno para dar uma volta e repentinamente soltava um golpe. O aprendiz recebia instruções de defesa e reconhecia a importância da observação, da concentração e do respeito ao ritual e aos mais velhos, ou seja, da oitiva.

Waldemar relatou que havia se formado mestre de capoeira com os ensinamentos de Telabi, Ricardo da Ilha de Maré, Siri de Mangue e Neco Canário Pardo. As rodas de capoeira dominicais aconteciam porque era o momento em que a maioria dos trabalhadores estava de folga. Havia um agregamento de bares, quitandas, bodegas, vendas, prática de capoeira e sambas, que constituíam pontos de animação e de sociabilização. Consequentemente, também havia o aumento do fluxo financeiro de determinada comunidade. Posteriormente, a partir dos anos 1960, comentou sobre as relações entre a indústria turística e a cultura popular afro-brasileira, evidenciando meios mais complexos de exploração econômica.

Em 1940, Waldemar começou a ensinar a capoeira no bairro da Liberdade, na rua do Pero Vaz, também próximo a um botequim. Devido à localidade em que ensinava, também era reconhecido por Waldemar da Liberdade ou do Pero Vaz. Esse mestre ensinava na roda, mas também ministrava treinos em outros dias. Inicialmente sua roda acontecia na sombra de um arvoredo, sendo posteriormente 
construído um barracão, o qual se assemelhava aos barracões dos candomblés bem como àqueles feitos pelos pescadores à beira-mar. Os encontros nesse local perpassaram as décadas seguintes, 1950 e 1960, num misto de rito profano e vício sagrado. (ABREU, 2003)

No referido local, também se reuniram capoeiristas famosos, a exemplo de Traíra, que era seu contramestre. Os capoeiristas chegavam ali vestidos de branco, com calça e paletó, lutavam a tarde toda, mostrando a periculosidade do próprio conhecimento, e não se sujavam. Waldemar era um mantenedor da ordem e do respeito no ambiente do barracão, autoridade reconhecida pela comunidade de capoeiras, pelos moradores em geral e até mesmo pela polícia. O canto era visto por esse mestre como um instrumento disciplinador e sedutor, para que não fosse necessário recorrer ao autoritarismo e à truculência.

De modo semelhante à organização da academia de Pastinha, também havia a figura do juiz, que tomava conta da roda, interrompendo um jogo, mudando os pares e, no caso de desobediência, expulsando da roda. Apesar do difícil acesso, o barracão do mestre Waldemar era visitado por turistas, estudiosos, intelectuais, artistas, folcloristas e jornalistas, funcionando como uma espécie de agência cultural nacional e internacional, assim como também foram as academias de Bimba e de Pastinha. Sobre as questões profissionais, esse capoeirista fez da venda do berimbau seu principal sustento financeiro até morrer.

É de conhecimento de todos a condição de pobreza por que passou esse mestre no período da velhice, sendo necessário que os custos de seu sepultamento fossem pagos por admiradores e ex-alunos. Waldemar relatou a briga que havia entre os capoeiristas pela disputa de mercado, muito em razão da falta de ética de alguns profissionais, vendo que a união entre os mesmos era necessária para que pudessem enfrentar o contexto em que estavam inseridos, como as demandas do turismo, do folclore, do comércio do entretenimento, dos bens culturais e do esporte.

Finalizando esta seção, é conveniente relatarmos que no barracão do mestre Waldemar a formação da orquestra era de três berimbaus, três pandeiros e um reco-reco; apesar de não ter influenciado mudanças em aspectos da capoeira, esse mestre tornou-se lendário por proporcionar vivência cultural num clima harmonioso de paz e fraternidade. (ABREU, 2003) 


\section{Considerações finais}

A partir dos objetivos traçados, foi possível conhecermos alguns elementos da expansão e do ensino da capoeira no século XX. Percebemos, notoriamente, uma grande contradição nesse período, pois a eminente ascensão social e cultural da capoeira baiana não favoreceu a conquista de direitos sociais básicos a inúmeros mestres de capoeira enquanto eram anciãos. Evidenciando que essa expansão aconteceu na informalidade.

A partir dessa constatação, pudemos refletir sobre o papel do educador de história e cultura afro-brasileira e dos povos indígenas brasileiros em ambientes diferenciados de ensino. Para além e evidenciando a importância da implementação da Lei $n^{\circ}$ 10.639/03 e $n^{\circ} 11.645 / 08$, a articulação de saberes da/na capoeira entre os diferentes mestres estudados nos expõem o elemento da diversidade metodológica de ensino e de diferenciadas concepções filosóficas sobre essa prática, entre elas a concepção esportivista e higienista.

Para fins de implementação da lei supracitada, a História dos mestres de capoeira são relevantes para constituição dos saberes que envolvem a prática pedagógica de professores de diferentes níveis de ensino e de diferentes disciplinas. O esforço desse artigo em selecionar passagens sobre o início do aprendizado, concepção de capoeira, narrativas do ensino propriamente dito e aspossíveiscorrelações com aspectos de economia e de gênero nos conduzem a um processo reflexivo sobre as motivações da expansão dessa prática. Tal expansão mostra-se profundamente relacionada à genialidade dos diferentes mestres de capoeira.

Em suma, estamos abordando o estudo desses mestres e a capoeira como um objeto de ensino interdisciplinar em toda Educação Básica. Observemos que, sob a concepção da capoeira como luta e defesa pessoal, a obra de Cobrinha Verde pode ser utilizada também para ensino de História Política e Social do século XX, visto que o contexto da história desse mestre está relacionado com o fenômeno do cangaço e da revolução de 1930.

O Samba de Batuque, elemento da cultura afro-brasileira, é apontada por mestre Cobrinha Verde, mestre Bimba e mestre Pastinha como uma prática antecessora da capoeira. Esse elemento, assim como outras práticas corporais que permeiam a capoeira, possui íntimas relações com disciplinas que trabalhem com o conceito de corpo e cultura, tais como Educação Física e Artes. 
Por conseguinte, através da capoeira os alunos de diferentes níveis de ensino se aproximam das reflexões sobre o multiculturalismo brasileiro. Observamos isso a partir de aspectos da cultura indígena $\mathrm{da} /$ na capoeira, que também podem ser estudados a partir dos escritos de mestre Pastinha. Esse mestre afirmava que a capoeira Angola era um esporte originado da dança primitiva dos caboclos, do batuque e do candomblé, assumindo também a contribuição de congoleses, moçambicanos e indígenas na formação de uma capoeira mais lúdica e defensiva.

Em todas as obras analisadas, o aspecto da oralidade e ancestralidade se faz presente como um princípio educacional essencial na prática educativa. Esse princípio pode ser retratado quando Cobrinha Verde rememora ensinamentos do seu mestre, ao acatar o pedido do lendário Besouro Mangangá de continuar repassando os ensinamentos da capoeira. Vale ressaltar que esse mestre inicia seu aprendizado aos 4 anos de idade pelo método da observação, podendo atestar adequabilidade do ensino da capoeira já na Educação Infantil.

Em Canjiquinha, capoeirista desde os 10 anos de idade, a oralidade é como um mecanismo de ensinar e aprender com alegria. Seus escritos nos remetem à reflexão sobre o encantamento pelo objeto de ensino e pelo corpo em movimento, visto que se utiliza dos conceitos de luta, arte, brincadeira e esporte, elementos presentes em todas fases de ensino. Podemos inferir, portanto, que a utilização da capoeira pode se manifestar de acordo com o objetivo de quem ensina, como naturalmente ocorreu no âmbito informal com os mestres estudados.

Por conseguinte, a capoeira como um esporte popular do Brasil faz parte do discurso desses mestres do século XX. Para mestre Noronha, iniciado na prática aos 8 anos de idade, esse fato se relaciona com a expansão da capoeira como prática esportiva, entre militares e civis, e isso seria a consequência da eficiência da mesma enquanto luta. Essa informação seria atestada pela passagem histórica do Batalhão Quebra Pedras, na Guerra do Paraguai. Esse mestre afirmava também que a capoeira foi educada na Bahia, pela excelência da oralidade dos seus mestres.

A projeção social de mestre Bimba, iniciado na capoeira aos 13 anos de idade, também possui relação com a eficiência dessa luta, mantendo e criando novoselementos ritualísticos na capoeira. Esse mestre de capoeira realizou inúmeras apresentações 
folclóricas para diferentes públicos, assim como Canjiquinha, Pastinha, Waldemar e outros capoeiristas célebres. Entretanto, o brilhantismo desse mestre advém, também, da capacidade de fazer uma prática de atividade física ser filosofia de vida para inúmeros capoeiristas ainda hoje.

Entre os sete mestres estudados, cinco iniciaram seus aprendizados na capoeira informalmente ena época do Ensino Fundamental. Diferentemente, mestre Waldemar iniciou a capoeira aos 20 anos de idade e defendeu a importância da observação, da concentração, do respeito ao ritual e aos mais velhos, denominando como oitiva esses princípios de ensino-aprendizagem. Esse mestre propiciou, destacadamente, um ambiente de liberdade, cultura, destreza e equilíbrio físico-emocional que atraiu atenção de turistas, artistas, folcloristas e intelectuais da Bahia. Para além disso, foi um capoeirista mantenedor da ordem e do respeito no local onde atuava.

Portanto, a partir do estudo sobre Histórias de Vida dos mestres selecionados evidenciamos as bases teórico-epistemológicas para ensino da capoeira em toda Educação Básica. Tanto pela característica interdisciplinar e pelo poder de afirmação cultural afro-indígena-brasileiro intrínseco à sua prática, como pela conexão da Capoeira com várias áreas de conhecimento. Além da capoeira ser um elemento de implementação das Leis $n^{0} 10.639 / 03$ e $n^{\circ}$ 11.645/08, que menciona as disciplinas de Educação Artística, de Literatura e História Brasileira, observamos, também, pelas fontes históricas consultadas, a profunda relação da capoeira com a área da Educação Física.

Finalizando esse artigo, consideramos que a Capoeira é um elemento de estudo interdisciplinar e que o mesmo pode ser incluído no Ensino Básico desde a Educação Infantil. A expansão da Capoeira e seus múltiplos mecanismos de resistência cultural podem ser compreendidos como uma condição sociobiológica vital, pois, ao passo que a mesma funciona como elemento propulsor de saúde, prazer e descanso, ela também oferece empoderamento cultural e conscientização histórico-social. Portanto,reafirmamos a importância de mais estudos sobre Capoeira-Educação, especificamente a partir da valoração dos ensinamentos deixados pelos escritos dos mestres que foram selecionados nesse estudo. 


\title{
Educational practices of capoeira in the early 20th century: reflections from biographical aspects of the masters of this art
}

\begin{abstract}
Capoeira, as a recreational, gymnastic, sportive and artistic manifestation, and/or personal defense system, has an educational potential that reveals itself by its perpetuation and cultural resistance over the centuries. In order to solve questions related to the genesis of the teaching methods of this practice, a qualitative analysis of the biographical aspects of some of the exponents of the Brazilian Capoeira in the early 20th century becomes relevant. Hence, technics of History research were adopted with the objective of creating reflections about the educational practices in capoeira. This study focused on the selection of primary biographical sources able to narrate the life stories of Cobrinha Verde, Canjiquinha, Bimba, Pastinha, Noronha and Waldemar, some of the countless capoeiristas from the Brazilian state of Bahia who lived the beginning of the social recognition, appreciation process and institutionalization of capoeira in the last century. The reflection was stimulated through the collection of information about the beginning of the learning and conception process of capoeira, the proper teaching narratives and possible correlations between economical and gender aspects. According to these categories of analysis, a directional study aimed at the comprehension of the educational historical context that involved the process of social affirmation of this practice was established.
\end{abstract}

Keywords: TeachingofCapoeira. Historyof Capoeira. Basic Education.

\section{Prácticas educativas de la capoeira en el siglo XX: reflexiones a partir de aspectos biográficos de maestros del arte}

Resumen: La capoeira, como forma de manifestación recreativa, gimnástica, deportiva, artística y/o sistema de defensa personal, tiene una potencialidad educativa que se pone de manifiesto por su característica de perpetuación y resistencia cultural a lo largo de los siglos. Con el objetivo de solucionar cuestiones referentes a la génesis de los métodos de enseñanza de esa práctica, se hace importante un análisis de la naturaleza cualitativa sobre aspectos de la biografía de algunos exponentes de la capoeira brasileña del siglo XX. Para tanto se realizaron procedimientos técnicos de investigación en Historia, cuyo objetivo se volcó a la reflexión de prácticas educativas de la capoeira. Se priorizó la selección de fuentes biográficas que narraran las historias de vida de Bimba, Canjiquinha, Cobrinha Verde, Noronha, PastinhayWaldemar, algunos de los muchos practicantes de capoeira que vivieron el comienzo del proceso de valorización social y de institucionalización de la capoeira en el siglo pasado. Se desarrolló la reflexión mediante el análisis de las informaciones sobre el inicio del aprendizaje de la capoeira, su concepción, narrativas de enseñanza y posibles correlaciones con aspectos de economía y de género. Según esas categorías de análisis, se facilitó la comprensión del contexto histórico educativo cerca del proceso de afirmación social de la práctica de la capoeira.

Palabras clave:Enseñanza de la Capoeira.Historia de la Capoeira. Educación Básico. 


\section{Referências}

ABREU, Frede. O barracão do mestre Waldemar. Salvador: Zarabatana, 2003.

BRASIL. Dossiê: inventário para registro e salvaguarda da capoeira como patrimônio cultural do Brasil. Brasília, DF: Iphan, 2007.

BURLAMAQUI, Aníbal. A ginástica nacional: capoeiragem metodizada e regrada. Rio de Janeiro: Edição do Autor, 1928.

CANJIQUINHA, Mestre. Canjiquinha, alegria da capoeira: eu sou a alegria da capoeira, na capoeira eu sou a alegria. Salvador: A rasteira, 1989.

CAPOEIRA, Nestor. Capoeira: os fundamentos da malícia. Rio de Janeiro: Record, 1998.

COUTINHO, Daniel. O ABC da capoeira Angola: os manuscritos do mestre Noronha. Brasília, DF: Centro de Informações e Documentos da Capoeira, 1993.

DARIDO, Soraya Cristina. Educação física na escola: implicações para a prática pedagógica. Rio de Janeiro: Guanabara Koogan, 2005.

DIAS, Luiz Sérgio. Quem tem medo de capoeira? Rio de Janeiro (18901904). Rio de Janeiro: Secretaria Municipal das Culturas, 2001.

MORAIS FILHO, Melo. Tipos da rua: capoeiragem e capoeiras célebres. In: MORAIS FILHO, M. Festas e tradições do Brasil. Belo Horizonte: Itatiaia; São Paulo: USP, 1979.p. 257-263.

PASTINHA, Mestre. Quando as pernas fazem miserêr: metafísica e prática da capoeira. Bahia: Pelourinho, 1960.

PIRES, Antônio Liberac Cardoso Simões. Bimba, Pastinha, Besouro de Mangangá: três personagens da capoeira baiana. Tocantins: Neab/ Grafset, 2002.

POLAK, Ymiracy Nascimento de Sousa; SANTANA, José Rogério; ARAÚJO, Helena de Lima Marinho Rodrigues. Dialogando sobre metodologia científica. 2. ed. Fortaleza: Edições UFC, 2014.

SANTOS, Marcelino dos. Capoeira e mandigas: Cobrinha Verde. Salvador: A rasteira, 1991.

SILVA, Sammia Castro. Protagonistas no ensino da capoeira no Ceará: relações entre lazer, aprendizagem e formação profissional. 2013. Dissertação (Mestrado em Educação Brasileira) - Faculdade de Educação, Universidade Federal do Ceará, Fortaleza, 2013. 